\title{
Nutritional Supplementation in Community-Dwelling Elderly People
}

\author{
Elena Mucci S.H.D. Jackson \\ Clinical Age Research Unit, Department of Clinical Gerontology, King's College Hospital, London, UK
}

\section{Key Words}

Mininutritional assessment $\cdot$ Nutritional intervention, elderly $\cdot$ Nursing home residents

\begin{abstract}
There is a large evidence base for nutritional intervention in acutely ill and post-operative hospitalised patients, but the evidence base for nursing home $(\mathrm{NH})$ residents is small. The prevalence of poor nutrition in $\mathrm{NH}$ s is high and baseline nutrition appears to be an important determinant of response to nutritional intervention. Residents with mininutritional assessment (MNA) scores above 23.5 tend to show less response than those with lower scores. This relates in part to failure to increase intake in the better nourished as well as to actual response to increased intake. At the low end of the MNA spectrum, the increasing prevalence of multiple pathologies tends to result in a reduced response, but randomised controlled studies in this group is probably not ethical. Most studies have tended to investigate the intermediate group with MNA scores of 17-23.5 or equivalent using other scales. Interventions have usually resulted in increased intake of calories and micronutrients. Other end points have variously shown responses including weight, immunological measures, infection rates, decubitus ulcers, falls and fracture rates. Many studies have been too small to demonstrate benefit and some are likely to have suffered from type I errors - showing benefit by chance. Poorly quantifiable variables likely to be of importance include the local environment and catering as well as pathophysiological variability.
\end{abstract}

Copyright $\odot 2008$ S. Karger AG, Basel

\section{KARGER}

Fax +4161306 1234

E-Mail karger@karger.ch

www.karger.com (c) 2008 S. Karger AG, Basel

0250-6807/08/0525-0033\$24.50/0

Accessible online at:

www.karger.com/anm

\section{Introduction}

Whilst it has long been recognised that ageing is associated with increasing prevalence of undernutrition, the investigation of interventions to reverse this trend are much more recent. Physiological changes of ageing affect nutritional requirements. Decline in muscle mass, sarcopaenia, leads to decreased strength and mobility, impaired balance and increased falls. Other changes in body composition include reduction in total body water, bone density and an increase in body fat:water ratio. Energy requirements decrease by about $100 \mathrm{kcal} /$ day per decade in proportion to the reduction in the amount of lean metabolising tissue. Estimated average requirement of energy for people over 75 years of age is $1,810 \mathrm{kcal} /$ day for females and 2,100 kcal/day for males [1]. With decreasing energy intake, micronutrient requirements are less easily met, and the diet needs to be particularly nutrient-dense to compensate. Physiological factors along with other factors frequently accompanying old age such as dental problems, impairment of taste, smell, cognition, dysphagia, chronic diseases and decline in psychological wellbeing may lead to inadequate food intake and malnutrition in elderly people [1].

Undernutrition is the most frequent type of malnutrition in elderly patients due to protein-energy deficiency. Epidemiological studies show that $5-10 \%$ of non-institutionalised older people are malnourished. This prevalence rises to $26 \%$ in patients who have been hospitalised for acute diseases, and reaches $30-60 \%$ in long-term care

Prof. S.H.D. Jackson

Clinical Age Research Unit, Department of Clinical Gerontology

King's College Hospital, Denmark Hill

London SE5 9RS (UK)

Tel. +44203299 3420, Fax +44203299 3441, E-Mail Stephen.Jackson@kcl.ac.uk 
units and nursing homes (NH). Not only is undernutrition poorly diagnosed, it is also badly treated: among elderly patients, abnormal weight loss was left untreated in more than $75 \%$ of cases [2]. In 1992, the economic cost to the United Kingdom National Health Service (NHS) of preventable malnutrition was estimated to be GBP 266 million a year, mainly due to increased bed occupancy and associated treatment costs [3].

As a result of these statistics, nutritional supplements are increasingly used both in the community and in hospital settings. The cost implications to health care providers are significant. Total expenditure on supplements in the NHS exceeded GBP 1.5 million in 1997.

\section{Types of Supplements Used in the Trials}

In a systematic review of oral nutritional supplements used in the community (451 elderly patients of 2,570 participants) Stratton [4] found that the supplements used in the majority of trials are liquid oral nutritional supplements (ONS) - either commercial sip-feeds or powders reconstituted to form a liquid supplement. A minority of studies used solid supplements (bars, puddings), powders added to normal food and drink and homemade supplements. The energy density of supplements varied considerably $(3.25-16.0 \mathrm{~kJ} / \mathrm{ml}$ ), as did their composition (protein-hydrolysate formulas, elemental formulas, mediumchain triacylglycerol-enriched, branched-chain amino acid-enriched and 'immuno-modulatory' formulas with extra arginine, n-3 fatty acids and nucleic acids). Standard formulas (approximately 15\% energy as protein, $35 \%$ energy as fat and 50\% energy as carbohydrate) were also commonly used. The amounts prescribed ranged from $<0.42$ to $>10.5 \mathrm{MJ} /$ day, for periods ranging from 1 week to over 2 years [4].

\section{Effect on Consumption and Appetite}

It is possible that nutritional supplementation may significantly reduce food intake and this would subsequently reduce the effectiveness of supplements. However, in a Cochrane review, 29 of 49 studies reported that supplementation increased daily protein intake and energy intake, or both [4]. The authors did point out that most trials included in the review had poor study quality. Supplement energy is largely additional to that taken orally with a mean increase in energy intake equivalent to $67 \%$ of the energy of the ONS consumed [4]. This contribution var- ied considerably according to the disease state and the BMI of the patients (e.g. 79\% of the ONS energy in those patients with BMI $<20 ; 28 \%$ of the ONS energy in those patients with BMI $>20$.

In patients with a mean BMI of 25 after 10 weeks of supplementation, the supplemented group did not increase their total energy intake significantly compared to the controls, despite high compliance with the supplements, which was offset by a reduction in normal food intake [6].

In a study of three groups of females (undernourished older subjects with a BMI $<18.5$, well-nourished older subjects, and well-nourished young subjects) fasting hunger ratings assessed using $10-\mathrm{cm}$ visual analogue scales were significantly lower in the undernourished group (i.e. feeling less hungry). After ingestion of the preload (143 g vanilla ice-cream, $280 \mathrm{kcal}$ ) both older groups were less hungry than the young subjects, but in the undernourished group food intake was not suppressed by the preload, whereas it was in the other groups. The authors hypothesised that reduced basal hunger and appetite may be a more important contributor to age-related undernutrition than increased (meal-induced) satiety [7].

\section{Effect on Body Structure and Weight}

The mean percentage weight change of patients receiving ONS is greater than that of unsupplemented control patients. This change appears to occur more frequently in individuals with $\mathrm{BMI}<20$ than in individuals with a BMI $>20[4]$.

A prospective controlled trial conducted in $\mathrm{NH}$ residents showed a significant increase in total energy intake and body weight on day 60 in supplemented groups of elderly people at risk of malnutrition (MNA 17-23.5) and malnourished $(\mathrm{MNA}<17)$. Supplementation in the malnourished group resulted in a mean MNA score increase (from $13.9 \pm 2.6$ to $17.1 \pm 3.9$ ) and a mean weight gain of $1.5 \pm 0.4 \mathrm{~kg}$ [8].

An RCT conducted of frail elderly people living at home showed that after a 17-week intervention with nutrient-dense foods, bone mineral density, total bone mass, and bone calcium increased slightly. Nutrient-dense products had no effect on lean or fat mass in frail elderly people. The authors hypothesised that extra micronutrients might correct existing deficiencies, and subjects with a better nutritional status might develop a higher activity level and in turn higher energy consumption. It is also possible that the intervention may not have been long 
enough. They also noted that energy-dense supplements reported to increase weight might be doing so via increasing the fat mass rather than muscle mass [9].

\section{Effect on Functional Capacity}

Few trials have demonstrated functional benefit with supplementation. In older people with COPD, significant improvement in exercise performance with supplementation has been demonstrated [10]. Reduced falls and increased activities of daily living in patients receiving supplements have been demonstrated. Functional benefits were typically observed more commonly in those patients with BMI $<20$ than in those with BMI $>20$.

An RCT comparing progressive resistance exercise training, multinutrient supplementation, both interventions, and neither in 100 frail NH residents showed that the supplement significantly increased body weight, but did not have a significant effect on whole-body fat-free mass and had no effect on mobility. The exercise intervention on the other hand significantly improved habitual gait velocity, stair-climbing ability, and the overall level of physical activity [6]. Total energy intake was significantly increased only in the group receiving both exercise training and nutritional supplementation. However, one of the exclusion criteria was unstable chronic illness. The study subjects were not undernourished and had a mean BMI of 25 .

Another RCT assessed psychological well-being in a group of frail but still independently living elderly people and found that neither exercise and/or enriched foods improved the outcome measure after a 7-week intervention [11].

There are few trials on the effect of nutritional supplementation on cognition. One prospective randomised controlled trial conducted on patients with Alzheimer's disease at risk of undernutrition on geriatric wards as well as in day care centres showed no significant changes in dependence and cognitive function with an increase in weight and fat-free mass after 3 months of oral nutritional supplementation [12].

\section{Effect on Mortality}

A meta-analysis of the effect of supplementation in nearly 7,000 patients in 25 trials regardless of setting has shown a barely significant $14 \%$ reduction in mortality [13]. Subgroup analysis suggested improved survival with supplementation in the presence of undernutrition, age over 75 and when patients/residents were offered 1,674 kJ or more per day.

\section{Effect on Morbidity and Complications}

Amongst older people living in the community rather than hospital in patients, reductions in infections, incomplete wound healing, total pressure ulcers, illness that led to discontinuation, exacerbations of chronic obstructive pulmonary disease and hospitalisation have tended not to reach statistical significance, although some individual trials have shown significant benefit [13].

One RCT in NH residents aged 65 and older showed that an experimental nutritional formula (containing higher levels of antioxidants, vitamins $\mathrm{E}, \mathrm{C}$, and $\beta$-carotene; $\mathrm{B}$ vitamins, selenium, and zinc than standard liquid nutritional supplements given to the control group) given for 4 weeks before and 6 weeks after an influenza vaccination enhanced immune function [14]. This was measured by increased influenza vaccine response and lymphocyte activation. Individuals receiving the experimental formula experienced less fever during the study (5 vs. $16 \% ; \mathrm{p}=0.02)$ and had fewer newly prescribed antibiotics ( 36 vs. 55 courses of antibiotics; $p=0.06$ ). However, there was a high drop-out rate: 65 of 157 consenting subjects (41\%) were withdrawn from the study and 44 of 65 (67\%) were withdrawn because of inadequate intake of the supplement. More patients who had a BMI of $<22$ or had diabetes completed the study in the intervention group. In a previous study on healthier independent and assisted-living seniors, who also showed benefit of the same experimental formula on the immune system, the most frequent reason for withdrawing from the study was unwanted weight gain [15].

The effect of supplementation on wound healing was assessed in a RCT involving 38 home-nursed elderly patients [16]. Patients had a range of wounds including ulcers, pressure sores, skin tears, lacerations, surgical wounds, and skin grafts. The mean BMI of the patients was $26 \pm 5.9$ with only $8 \%$ being severely malnourished at baseline. One group received 237 and the other $474 \mathrm{kcal}$ of supplementation a day for 4 weeks. Both groups achieved a significant decrease in wound depth score at the end of the intervention. However, a greater decrease in wound exudate volume score and decrease in wound area reached significance only in the $474-\mathrm{kcal}$ group. There was also a significant increase in the MMSE in the 
same group $(p=0.05)$. The improvements in MMSE score also increased as wounds became more shallow $(\mathrm{p}=0.002)$ and BMI improved $(\mathrm{p}=0.008)$.

\section{Compliance}

The literature suggests that under normal conditions acceptance of supplements can be a problem for elderly people. This might be due to an effect on gastrointestinal disturbances, such as nausea, vomiting, diarrhoea, poor appetite or other reasons. Larsson et al. [17] found that 39 of 197 patients refused the supplement and were withdrawn from the study and therefore not included in the analysis.

In long-term care settings where the residents tend to be frail and increasingly dependent, limited staffing levels might result in inappropriate dispensing of the supplements and/or little assistance to encourage consumption. A NH study found that only $75 \%$ of oral liquid supplements were dispensed as ordered and 55\% of residents consumed the supplement as ordered [18]. In a recent study of 132 supplemented NH residents, NH staff spent an average of less than 1 min per person encouraging the consumption of supplement between meals [19]. The average amount consumed was $144 \pm 119 \mathrm{kcal}$. During the 2 observation days 12 patients consumed $0 \mathrm{kcal}$ in response to supplement delivery. The proportion of participants who received a supplement consistent with their orders with respect to frequency (during meals, between meals, or both) was 7\%. Participants received an average of 6 minutes (per person per meal) of assistance from $\mathrm{NH}$ staff to encourage meal intake.

\section{Non-Supplementation Interventions}

In a cross-sectional descriptive study of 105 residents from three NHs, their family members' preferences were analysed using a questionnaire that consisted of 15 forcedchoice comparisons. Food quality improvements, feeding assistance and the provision of multiple small meals and snacks throughout the day were the strongly preferred approaches as opposed to nutritional supplementation which was consistently chosen last. Interestingly, $63 \%$ of residents in this study had chart orders to receive oral supplements [20]. Residents in NHs receiving family support ate and drank much better than residents who had no family support [21].
Individualising patients' care by serving food they want and enjoy, or familiar ethnic food can also help to improve nutritional status [21]. Some trials have reported improvements even in the control groups possibly due to the effect of socialising and attention $[2,12]$.

\section{Economic Analysis}

In a NH study, 313 supplement observations were made on 40 residents over 3 days. The authors found that $35 \%$ of dispensed supplements were not consumed (i.e. wasted) during the observation period. The average daily cost of supplement wastage was USD 19.15 or approximately USD 575 per month for the 40 residents receiving supplements. The authors concluded that more effective ways of providing nutritional supplements are needed [22].

An observational pharmaco-economic study with 12 months of follow-up assessed two groups of GPs based on their prescribing practice: group 1 with rare and group 2 with frequent prescriptions of ONS in elderly malnourished patients (mean BMI 20) living either at home or in institutions. Although expenditure on supplements was higher in group 2 than in group 1 (EUR 565 vs. EUR 37 per patient over 12 months' follow-up), medical care consumption was higher in group 1, with patients having more hospital admissions, nurse and GP visits. This resulted in overall higher mean health care costs in group 1 - EUR 2,694 versus EUR 2,499 in group 2, with savings of EUR 195 per patient over 12 months' follow-up in group 2. The authors recognised that the study was observational: it would not have been ethical to refrain from providing nutritional support to patients diagnosed with malnutrition [2].

\section{Conclusions}

Supplementation produces a small but consistent weight gain in community-dwelling elderly patients both living at home and in long-term care settings. There is some evidence to suggest improvement in functional status - those who are most malnourished at baseline gain greater benefit from intervention in terms of both weight gain and improved function. Exercise is also required to improve muscle strength and subsequently functional status. The supplements are reasonably well tolerated and supplementation resulted in increased total energy intake. Problems with compliance occur, but there is no 
evidence that participants at home are less compliant than those in hospital or long-term care. A small effect on mortality has been demonstrated, but the effect on complications has not been clearly demonstrated.

The results of the studies should be interpreted with caution as in these studies research staff provided supplements and encouragement to promote consumption one to three times daily. In practice, there is little time and few staff to provide such encouragement and compliance can be a problem with patients not wishing to take supplements.
Simple measures such as providing family-style mealtimes in a comfortable dining area with nicely dressed tables, choice of hot cooked food and friendly attentive staff prevented a decline in the quality of life, physical performance, and body weight of $\mathrm{NH}$ residents without dementia [23].

\section{Disclosure Statement}

The authors have no conflicts of interest.

\section{References}

1 Garrow IS, James WPT, Ralph A: Human Nutrition and Dietetics, ed 10. London, Elsevier Health Sciences, 2000

$\checkmark 2$ Arnaud-Battandier F, Malvy D, Jeandel C, Schmitt C, Aussage P, Beaufrere B, Cynobe L: Use of oral supplements in malnourished elderly patients living in the community: a pharmaco-economic study. Clin Nutr 2004; 23:1096-1103.

3 Lennard-Jones JE: A Positive Approach to Nutrition as Treatment. London, King's Fund Centre, 1992

4 Stratton RJ: Summary of a systematic review on oral nutritional supplement use in the community. Proc Nut Soc 2000;59:469-476.

5 Milne AC, Potter J, Avenell A: Protein and energy supplementation in elderly people at risk from malnutrition. Cochrane Database of Systematic Reviews 2005, Issue 1, Art No: CD003288. DOI:10.1002/14651858. CD003288.pub2.

-6 Fiatarone MA, O'Neil EF, Ryan ND, Clementa KM, Solares GR, Nelson ME, Roberts SB, Kehayias JJ, Lipsitz LA, Evans WJ: Exercise training and nutritional supplementation for physical frailty in very elderly people. N Engl J Med 1994;330:1769-1775.

7 7 Sturm K, Macintosh CG, Parker BA, Wishart J, Horowitz M, Chapman IM: Appetite, food intake, and plasma concentrations of cholecystokinin, ghrelin, and other gastrointestinal hormones in undernourished older women and well-nourished young and older women. J Clin Endocrinol Metab 2003;88: 3747-3755.

-8 Arnaud-Battandier F, Lauque S, Mansourian R, Guigoz Y, Paintin M, Nourhashemi F, Vellas B: Protein-energy supplementation in malnourished nursing-home residents: a controlled trial. Age Ageing 2000;29:51-56.
9 De Jong N, Marijke JM, Paw CA, de Groot LCPGM, Hiddink GJ, van Staveren WA: Dietary supplements and physical exercise affecting bone and body composition in frail elderly persons. Am J Publ Health 2000; 90:6

10 Steiner MC, Barton RL, Singh SJ, Morgan MD: Nutritional enhancement of exercise performance in chronic obstructive pulmonary disease: a randomised controlled trial. Thorax 2003;58:745-751.

$\checkmark 11$ Paw CA, de Jong N, Schouten EG, van Staveren WA, Kok FJ: Physical exercise or micronutrient supplementation for the wellbeing of the frail elderly? A randomised controlled trial. Br J Sports Med 2002;36 126-131

12 Lauque S, Arnaud-Battandier F, Gillette S, Plaze JM, Andrieu S, Cantet C, Vellas B: Improvement of weight and fat-free mass with oral nutritional supplementation in patients with Alzheimer's disease at risk of malnutrition: a prospective randomized study. J Am Geriatr Soc 2004;52:1702-1707.

13 Milne AC, Avennel A, Potter J: Meta-analysis: protein and energy supplementation in older people. Ann Intern Med 2006;144:3748.

14 Langkamp-Henken B, Bender BS, Gardner EM, Herrlinger-Garcia KA, Murasko DM, Schaller JP, Stechmiller JK, Thomas DJ, Wood SM, DeMichele SJ: Nutritional formula improved immune profiles of seniors living in nursing homes. J Am Geriatr Soc 2006;54:1861-1870.

15 Langkamp-Henken B, Bender BS, Gardner EM, Herrlinger-Garcia KA, Kelley MJ Murasko DM, Schaller JP, Stechmiller JK, Thomas DJ, Wood SM: Nutritional formula enhanced immune function and reduced days of symptoms of upper respiratory tract infection in seniors. J Am Geriatr Soc 2004; 52:3-12.
6 Collins CE, Kershaw J, Brockington S: Effect of nutritional supplements on wound healing in home-nursed elderly: A randomised trial. Nutrition 2005;21:147-155.

17 Larsson J, Unosson M, Ek AC, Nilsson L, Thorslund S, Jurulf P: Effect of dietary supplement on nutritional status and clinical outcomes in 501 geriatric patients: a randomised study. Clin Nutr 1990;9:179-184.

18 Kayser-Jones J, Schell ES, Porter C, Barbaccia JC, Steinbach C, Bird WF, Redford M, Pengilly K: A prospective study of the use of liquid oral dietary supplements in nursing homes. J Am Geriatr Soc 1998;46:13781386

19 Simmons SF, Patel AV: Nursing home staff delivery of oral liquid nutritional supplements to residents at risk for unintentional weight loss. J Am Geriatr Soc 2006;54:13721376 .

20 Simmons SF, Lam HY, Rao G, Schnelle JF: Family members' preferences for nutritional interventions to improve nursing home residents' oral food and fluid intake. J Am Geriatr Soc 2003;51:69-74.

21 Kayser-Jones J: Mealtime in nursing homes: the importance of individualized care. J Gerontol Nurs 1996;22:26-31; quiz 51.

22 Remsburg RE, Sobel T, Cohen A, Koch C, Radu C: Does a liquid supplement improve energy and protein consumption in nursing home residents? Geriatr Nurs 2001;22:331335.

23 Nijs K, de Graaf C, Kok FJ, van Staveren WA: Effect of family style mealtimes on quality of life, physical performance, and body weight of nursing home residents: cluster randomised controlled trial. Br Med J 2006;332: 1180-1184. 